\title{
Etretinate Improves Localized Porokeratosis of Mibelli
}

Janis P. Campbell, M.D., and John J. Voorhees, M.D.

ABSTRACT: A 60-year-old woman with plaque-type psoriasis of 30 years' duration was treated with etretinate. The lesion resolved while the patient was on the drug and continued to resolve after she had discontinued therapy. The continuation of resolution after the patient had discontinued the drug is probably due to its long half-life.

Since the original descriptions of porokeratosis in 1893 by Mibelli ${ }^{1}$ and Respighi, ${ }^{2}$ various therapeutic modalities have been sought. Excision, irradiation, carbon dioxide snow, silver nitrate cautery, and currettage have been tried as well as UV light, roentgen therapy, keratolytics, thyroid supplements, topical and intralesional steroids, $5 \%$ FU ointment, and vitamin $\mathrm{A}$ (300,000 $U$ every day for 12 weeks). ${ }^{3-8}$ Recently, two reports have appeared in the literature concerning remissions of porokeratosis of Mibelli in response to aromatic retinoid therapy (RO 109359). ${ }^{9 .}{ }^{10}$ We have had the opportunity to follow a patient with localized porokeratosis of Mibelli of 10 years' duration who, when treated with retinoid therapy (RO 109359) for psoriasis, experienced slow lesion resolution. To our knowledge, this is the third reported case in the literature.

\section{Case Report}

A 60-year-old white woman had plaque-type psoriasis of 30 years' duration. For the past 10 years, she has been followed at the University of Michigan Dermatology Department for psoriasis; during this time, she was noted to have an area of classic porokeratosis of Mibelli on the inner aspect of her left leg (Fig. 1). Early treatment for her psoriasis included modified Goeckerman therapies, PUVA, and methotrexate, none of which caused any changes in her lesion of porokeratosis. Because of early changes of portal fibrosis on a liver biopsy, methotrexate therapy was discontinued. After a 4-week wash-

\footnotetext{
Address for correspondence: Janis P. Campbell, M.D, 142320th Street N.W., Calgary, Alberta, T2N 2K7 Canada.
}

From the University of Michigan Medical Center, Department of Dermatology, Ann Arbor, Michigan

out period, she was started on an experimental protocol with etretinate for psoriasis. Because of its incidental nature and classical appearance, no biopsy was performed on the lesion of porokeratosis.

In September 1981 , she began $1 \mathrm{mg} / \mathrm{kg} /$ day $(80 \mathrm{mg} /$ day) for a period of 2 months. Her dose was then dropped to 50 $\mathrm{mg} /$ day $(0.6 \mathrm{mg} / \mathrm{kg} /$ day $)$ as per protocol. When the patient was seen after 5 months of therapy, the area of porokeratosis was covered with a red erosion and she complained of pruritus (Fig. 2). In March 1982, the drug was discontinued for a 3-month

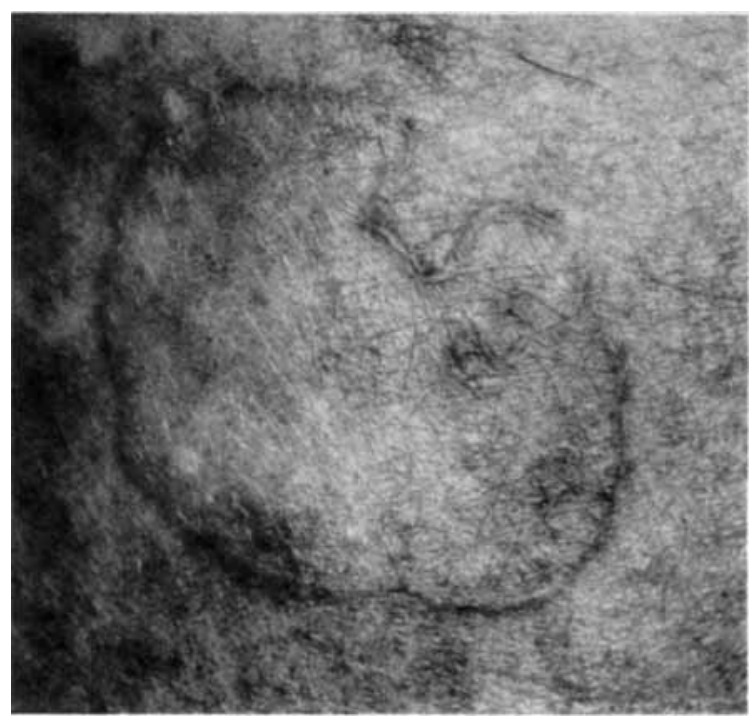

FiG. 1. Classic porokeratosis of Mibelli before treatment with etretinate. 


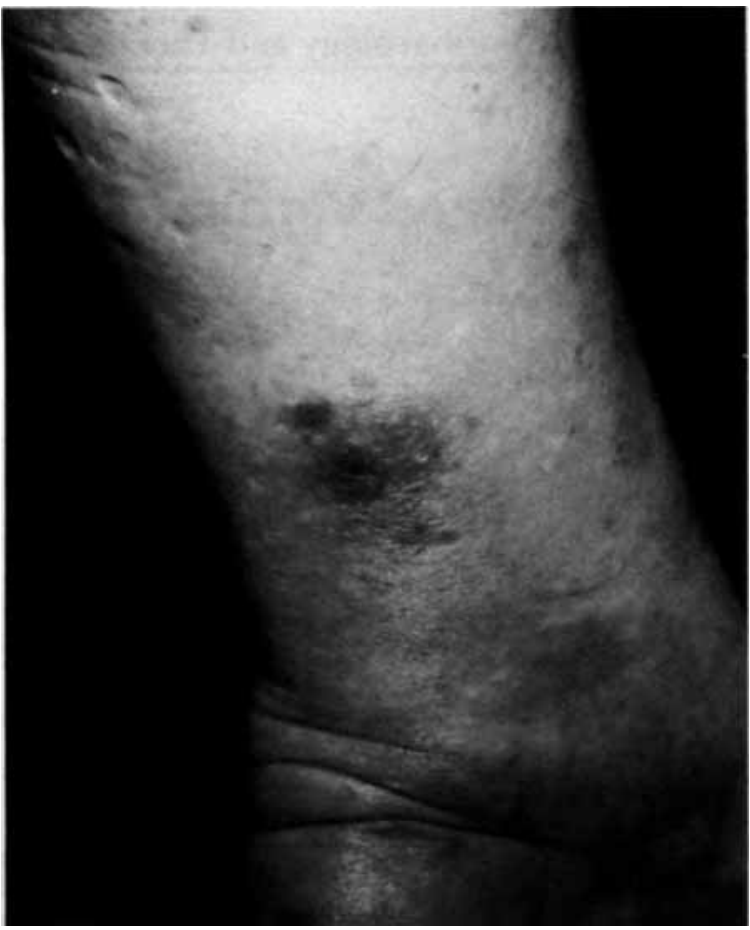

FIC. 2. Erythema and erosions at site of porokeratosis of Mibelli after 5 months of therapy.

wash-out period. The lesion continued to show increasing erythema, induration, and pruritus. In June 1982, the drug was resumed at $1 \mathrm{mg} / \mathrm{kg} /$ day for 2 months and then decreased to $0.6 \mathrm{mg} / \mathrm{kg} /$ day. Because of a granulation tissue response around her toenails, she elected to discontinue etretinate therapy in September 1982. The lesion at that time measured 2 $x 2 \frac{1}{2} \mathrm{~cm}$ and was quite erythematous with mild induration at the sites of erythema. The initial scaling noted at this site when the inflammation began had resolved.

The patient was seen again in follow-up in January 1983. There was no evidence of the porokeratosis of Mibelli (Fig. 3). Mild scarring was seen at the prior lesion site. The area has remained clear for the past 17 months.

\section{Discussion}

Two recent reports indicate improvement of porokeratosis with etretinate therapy. Bundino and Fina ${ }^{9}$ report the use of RO 109359 in widespread porokeratosis of Mibelli using dosages of $75 \mathrm{mg} /$ day for 10 days, then $50 \mathrm{mg} /$ day for 3 weeks. The drug caused general improvement in their study. One patient complained of pruritus at the site of lesions once therapy was started. The first changes occurred after a week, at which time the lesions became inflamed and initial desquamation appeared. During this time, some of the hyperkeratosis crumbled away. After another week of therapy,

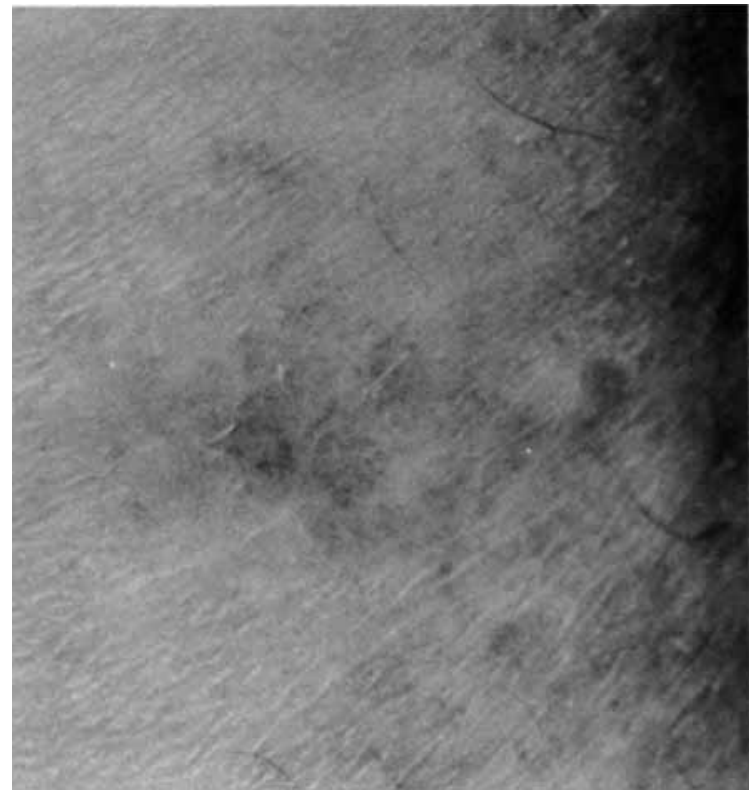

FIC 3. Resolution of porokeratosis of Mibelli with mild scarring at prior lesion site.

the rim became less evident. Better results were noted in lesions on the face, thighs, and arms. In a second case, the hyperkeratotic scales disappeared but the lesion remained indurated. Some lesions resolved with residual hyperpigmentation but no scar. A daily dose of 25 $\mathrm{mg}$ /day kept most areas clear with only a few lesions relapsing, while suspension of treatment allowed more recurrence after 3-4 weeks. Bundino and Fina postulated that etretinate had a morbistatic action, since ultrastructural changes peculiar of porokeratosis of Mibelli (vaculated or dyskeratotic cells) could still be found in clinically improved lesions and the lesions clinically recurred after the suspension of treatment.

Pehamberger and Konrad ${ }^{10}$ treated a fifteen-year-old white boy with linear porokeratosis of Mibelli with etretinate at $1 \mathrm{mg} / \mathrm{kg} /$ day for 7 weeks, during which time the lesions decreased in thickness and thinning of the elevated ridges without any pronounced inflammatory reaction was noted. The drug was decreased to $0.5 \mathrm{mg}$ / $\mathrm{kg} /$ day for 5 weeks, at which time only residual hyperpigmentation remained visible. No mention is made in the report of long-term remission if the drug was discontinued.

Our present case differs from previously reported cases in several ways. First, our case was a localized form of porokeratosis of Mibelli. Those cases reported previously were of a disseminated or a linear variety.

Second, it took 20 weeks of therapy before erythema 
was first noted at the lesion site. This inflammatory reaction then persisted for many months before gradual resolution of the lesion occurred. This is a much slower clearing time than that reported by either Bundino or Pehamberger ( 4 weeks and 7 weeks, respectively); however, the same sequence of clinical improvement seemed to follow. Pruritus, decreased hyperkeratosis, and inflammation occurred in all cases.

Third, our patient's porokeratosis continued to resolve during periods when she was off the drug. Further, the site has remained clear for 17 months off therapy. This differs from the rapid recurrence reported by Bundino when etretinate therapy was discontinued. Spontaneous resolution of the porokeratosis of Mibelli cannot be ruled out, yet the frequency of spontaneous resolution of the porokeratosis of Mibelli cannot be determined by a review of the literature. We believe that the continuation of resolution while off the drug can be attributed to etretinate's long half-life of elimination, especially in our patient, who was on chronic long-term therapy. Following cessation of long-term therapy, an individual may get significant drug levels in plasma from some deep storage compartment, such as the liver." This would explain why the site on our patient continued to clear while off therapy.

The histogenesis of porokeratosis has been attributed to a clone of abnormal epidermal cells located at the base of the parakeratotic column, which forms the cornoid lamella. ${ }^{12}$ Etretinate's effect on porokeratosis probably stems from its action as "a general regulator of epidermal phenomena related to dysfunction of epider- mal cell differentiation, keratin synthesis, and desquamation of corneocytes." 13

\section{References}

1. Mibelli V. Contributo allo etudio della 'percheratosi dei canali sudoriferi (porokeratosis). G Ital Mal Veneree Pelle. 1893;28: 313-335.

2. Respighi E. Di una 'pereheratosi non ancora descretta. G Ital Mal Veneree Pelle. 1893;28:356-386.

3. Wright CS. Porokeratosis: report of a case. Arch Dermatol Syphilol. 1921:4:469-489.

4. Barker LP, Huber W, Hallinger ES. Porokeratosis of Mibelli. NY State M I Med. 1948;48;1909-1914.

5. Chisa N. Porokeratosis of Mibelli. Arch Dermatol. 1968;98: 325-326.

6. Shatin H. Porokeratosis of Mibelli. Arch Dermatol. 1969;99: 248-249.

7. Eyre WG, Carson WE. Linear porokeratosis of Mibelli. Arch Dermatol. 1972;105:426-429.

8. McDonald SG, Peterka ES. Porokeratosis (Mibelli): treatment with topical 5-fluorouracil. I Am Acad Dermatol. 1983;8: 107-110.

9. Bundino S, Fina AM. Disseminated porokeratosis Mibelli treated with RO 10-9359: a study of two cases with ultrastructural remarks. Dermatologica. 1980;160:328-336.

10. Pehamberger $H$, Konrad $K$. Treatment with an oral aromatic retinoid in linear porokeratosis. Dermatologica. 1980;160: 270-274.

11. Paravicini U. Pharmacokinetics and metabolism of oral aromatic retinoids. In: International Dermatology Symposium (1980: Berlin, Germany): Retinoids, advances in basic research and therapy. Berlin: Springer-Verlag, 1981;13-20.

12. Reed RI, Leone P. Porokeratosis: a mutant clonal keratosis of the epidermis. Arch Dermatol. 1970;101:340-347.

13. Schultz-Ehrenburg U, Orfanos CE. Light and electron microscopic changes of human epidermis under oral retinoid treatment. In: International Dermatology Symposium (1980: Berlin, Germany): Retinoids, advances in basic research and therapy-Berlin: Springer-Verlag, 1981,85-92.

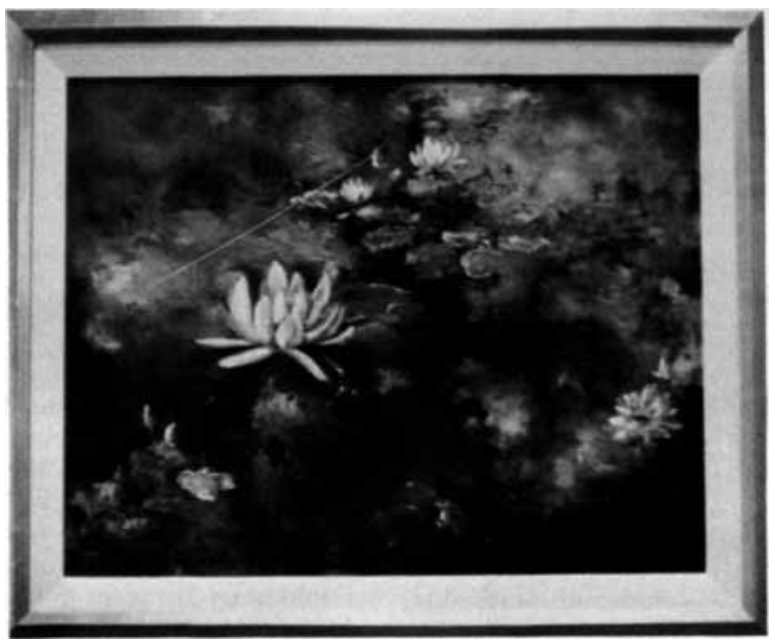

"Waterlilies." Barbara Berman. Honorable Mention, 1984. Exhibit of the American Academy of Dermatology. Photograph courtesy of Hoechst-Roussel Pharmaceuticals, Inc. 